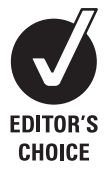

- Table A1 is published online only at http://jech.bmj.com/ content/vol62/issue8

${ }^{1}$ Institute of Education, University of London, London, UK: ${ }^{2}$ Department of Public Health and Policy, London School of Hygiene and Tropical Medicine, London, UK:

${ }^{3}$ Department of Social

Medicine, University of Bristol, Bristol, UK

Correspondence to:

Ms A Sorhaindo, Department of Public Health and Policy, London School of Hygiene and Tropical Medicine, WC1E 7HT London, UK; annik.sorhaindo@Ishtm.ac. uk

Accepted 23 November 2007

\title{
Dietary patterns related to attainment in school: the importance of early eating patterns
}

\author{
L Feinstein, ${ }^{1}$ R Sabates, ${ }^{1}$ A Sorhaindo, ${ }^{2}$ I Rogers, ${ }^{3}$ D Herrick, ${ }^{3} \mathrm{~K}$ Northstone, ${ }^{3} \mathrm{P}$ Emmett ${ }^{3}$
}

\section{ABSTRACT}

Objectives: To empirically test the impact of dietary intake at several time points in childhood on children's school attainment and to investigate whether any differences in school attainment between children who ate packed lunches or school meals was due to who these children were, their pre-school dietary patterns, or to what they ate at school.

Design: Using longitudinal data available in the Avon Longitudinal Study of Parents and Children (ALSPAC), multivariate linear regression was used to assess the relative importance of diet at different ages for school attainment.

Main outcome measures: Three indicators of school attainment were used: at ages 4-5 entry assessments to school, at ages 6-7 Key Stage 1 national tests and at ages 10-11 Key Stage 2 national tests. These outcome variables were measured in levels as well as in changes from the previous educational stage.

Results: The key finding at age 3 was that "junk food" dietary pattern had a negative association with the level of school attainment. A weak association remained after controlling for the impact of other dietary patterns at age 3 , dietary patterns at ages 4 and 7 and other confounding factors. The authors did not find evidence that eating packed lunches or eating school meals affected children's attainment, once the impact of junk food dietary pattern at age 3 was accounted for in the model.

Conclusions: Early eating patterns have implications for attainment that appear to persist over time, regardless of subsequent changes in diet.

The content and quality of food eaten is related to developmental, cognitive and behavioural outcomes that are important in childhood for health and well-being, but also for specific experiences, such as school life. ${ }^{1-4}$

This issue has had a high profile in the UK partly as a result of the Jamie's School Dinners television programme originally broadcast in 2005 . The programme raised awareness about the poor nutritional content of school meals and children's preference for foods that are high in energy, fat, sugar and salt. Celebrity chef Jamie Oliver worked with staff and students in UK schools to improve the nutritional content of school meals and began a national campaign to highlight the importance of nutrition for children's well-being and to improve the nutritional quality of food offered in schools. ${ }^{5}$ The UK government increased funding for school meals and instituted an agency to advise schools on nutritional standards. ${ }^{6}$ Staff in schools that managed to improve the nutritional content of their meals reported improvements in students' behaviour in the classroom that they felt was related to the change in diet. ${ }^{\text {? }}$
Via their effects on cognition, behaviour and physical health, the foods children eat have the potential to impact upon engagement in school and consequent attainment. Previous research on breakfast has focused on the short-term effects of nutrition on cognition and behaviour for children. ${ }^{8-10}$ There is also evidence that early diet affects children's ability to think and perform in the long term. ${ }^{11-13}$ This suggests that appropriate early childhood diets can be important for subsequent school outcomes. However, we are unaware of any studies linking early nutrition specifically to later school attainment.

This paper addresses two research questions. First, what is the relative importance of early diet versus later diet in predicting school attainment? Second, spurred by the recent debate about the role of schools in determining what children eat and research showing that, on average, the nutritional content of school meals is superior to that of packed lunches, we ask: does school attainment differ between children who eat packed lunches and children who eat school meals, conditioned on their pre-school dietary patterns $?^{14}$

\section{METHODS}

\section{Data and sample}

The Avon Longitudinal Study of Parents and Children (ALSPAC) is an ongoing population-based study designed to investigate the effects of environmental, genetic and other influences on the health and development of children. ${ }^{15}$ Eligible participants were pregnant women resident in the former Avon health authority in South West England who were expected to deliver between 1 April 1991 and 31 December 1992. A cohort of 14541 pregnant women were recruited resulting in 13988 children (alive at 12 months old). Self-completion questionnaires were administered to the mothers during pregnancy and at various ages of the child. Ethical approval for the study was obtained from the ALSPAC Law and Ethics Committee and the Local Research Ethics Committees.

\section{Outcome variable: school attainment}

In the UK, each member country (England, Wales, Scotland and Northern Ireland) sets standards for what children should be taught at particular ages or Key Stage (KS). Children are then assessed for their attainment of the set curricula at each age or stage. KS scores obtained from the relevant education authorities in the National Pupil Database (NPD) were matched to the ALSPAC data. We used the Key Stage 2 (KS2) results for English, maths and science, administered when children are 10-11 years old, to assess school attainment. 
In ALSPAC, some data on KS scores are missing because the NPD does not cover children in private schools (4.3\% of pupils); matching was based on the child's name, date of birth and current postcode, so perfect matching was not always achieved; children initially included in ALSPAC who subsequently moved outside of England were not covered by the NPD. We do not know the proportion of pupils missing because of the last two explanations.

We used KS1 assessments of reading, writing, and maths, administered when the children were 6-7 years old, and on entry assessment in maths, reading, language, and writing, administered by schools and set by local education authorities when the children were 4-5 years old to measure attainment prior to KS2. This allowed for investigation of the impact of dietary patterns on attainment at different ages and on the change in school attainment. Entry assessments were not national or compulsory during the period of data collection so information was available for only two-thirds of the children.

\section{Dietary data}

Mothers, or main female carers, completed food frequency questionnaires (FFOs) about their child's consumption of foods and beverages when the child was 38 months (about 3 years old), 54 months (about 4 years old) and 81 months (about 7 years old). Of the 13988 children in ALSPAC, dietary information at all three ages was only available for 7703 children $(55 \%)$.

At 81 months, mothers reported whether their child ate meals served at school or packed lunches provided from home and the frequency with which they did each, recorded as either rarely, once in 2 weeks, once a week, two to four times a week or 5 days a week. Of these children, 29 per cent ate school dinners 5 days a week and nearly half $(46 \%)$ ate packed lunches 5 days a week.

Of the 7703 children for whom dietary information was collected, 74 per cent had information on both KS2 and KS1 scores. The final study sample consisted of 5741 children with complete information on food frequencies and both school attainment scores results (41\%).

\section{Socioeconomic, demographic and lifestyle confounders}

As both diet and achievement are influenced by a number of socioeconomic, demographic and lifestyle factors, such factors were controlled for in the analysis to attempt to remove confounding bias. These variables related to measurements taken prior to, or at the time of, the food intake, that is at ages 3-4 and before our measurements of school attainment. For all these variables, we included a missing category to avoid further loss of data.

Relevant sociodemographic information about the child included whether the child was a singleton or multiple birth, their gender and ethnicity, birth weight and the number of siblings at birth. Information on the mother included whether she felt she had difficulties affording food, her employment status, whether she had a partner, her highest educational qualifications at the time of birth, her socioeconomic group (SEG) (defined as professional for SEG I, managerial and technical for SEG II, skilled manual and nonmanual for SEG III, partly skilled for SEG IV and unskilled for SEG V), whether she smoked during her pregnancy, whether she was a vegetarian when the child was born and her age at delivery.
Other variables included mother's parenting, breastfeeding, the household weekly income, housing tenure, whether the child watched children's television programmes and the HOME score, an indicator of the cognitive stimulation and emotional warmth in the home environment. ${ }^{16}$

Table 1 lists the frequencies of the confounding variables used in this analysis, comparing those in our sample with the whole cohort. Overall, differences between the means are fairly small. The study sample contains more white male children, more children who watched television, more mothers from the middle socioeconomic group SEG (III), fewer mothers from the lowest SEG (IV or V), more mothers with secondary educational qualifications, fewer mothers with educational qualifications below secondary level and fewer mothers who smoked during pregnancy.

\section{Statistical methods}

Factor analysis (FA) was used to identify dietary patterns from the FFQ on 43 foods at 38 months, and on 57 foods at 54 and 81 months. FA reduces data by forming linear combinations of the original observed variables, thus grouping correlated variables and identifying underlying patterns in the data. In these data, three components or dietary patterns were identified for each time point. They were described as "junk food" characterised by high-fat processed foods (sausages, burgers and poultry products), snack foods high in fat and/or sugar (such as crisps, sweets, chocolate, ice lollies and ice creams) fizzy drinks and the number of takeaway meals eaten per month; "healthconscious" characterised as vegetarian foods, nuts, salad, rice, pasta, fruit, cheese, fish, cereal, water and fruit juice; and "traditional", typically meat and cooked vegetables. ${ }^{17} 18$ Table A1 in the appendix (available online) provides further information on the dietary intake among children with diets high and low in "junk food" at 54 months.

A score was created for each child by multiplying the factor loadings by the corresponding standardised value for each food and summing across the food types for each of the three dietary patterns. The score has a mean of 0 and a higher score indicates closer association to that dietary pattern. ${ }^{19}$ An indicator variable was also generated to differentiate between children who ate school dinners 5 days a week, those having packed lunches 5 days a week and those having a combination of packed lunches and school meals.

FA was also performed on the individual KS2 assessments to obtain an overall score with loadings of 0.79 for English, 0.86 for maths and 0.89 for science. Overall scores were also obtained for KS1 and entry assessments. Factor loadings for KS1 were 0.88 for reading, 0.87 for writing and 0.74 for maths, and for entry assessments 0.79 for reading, 0.70 for writing, and 0.70 for maths. The resulting scores had a mean of 0 and standard deviation of 1 , thus a higher score indicates a higher result on overall tests.

Multivariate linear regression was used to assess the relative importance of diet at different ages for school attainment, allowing for the cluster of multiple births. The dependent variables, attainment score at different ages, were regressed against the dietary pattern scores, controlling for observable confounding factors. In this way, we assessed the relative importance of dietary patterns at different ages in predicting school attainment at different ages. The first model estimated the impact of dietary patterns at ages 3 and 4 on entry assessments (age 4-5) controlling for socioeconomic and demographic variables. The second model estimated, separately, 
Table 1 Descriptive statistics of confounding variables

\begin{tabular}{|c|c|c|}
\hline Child variables & $\begin{array}{l}\text { Sample available to } \\
\text { this study }\end{array}$ & $\begin{array}{l}\text { Whole ALSPAC } \\
\text { cohort }\end{array}$ \\
\hline Gender (\% male) & 49.9 & $47.8^{*}$ \\
\hline Ethnicity (\% white) & 94.4 & $77.6^{*}$ \\
\hline Birth weight (mean, $\mathrm{kg}$ ) & 3.4 & $3.3^{*}$ \\
\hline Twin (\%) & 1.1 & 1.2 \\
\hline Birth order (mean, range) & $1.7,1-14$ & $1.8,1-14^{*}$ \\
\hline \multicolumn{3}{|l|}{ Mother variables } \\
\hline \multicolumn{3}{|l|}{ Smoking in pregnancy (\%) } \\
\hline Never & 84.1 & $80.0^{*}$ \\
\hline 1-9 cigarettes/day & 6.5 & $7.7^{*}$ \\
\hline More than 9 cigarettes/day & 9.5 & $12.2^{*}$ \\
\hline \multicolumn{3}{|l|}{ Education (\%) } \\
\hline Below secondary (below 0 level) & 21.9 & $25.4^{*}$ \\
\hline Secondary (0 level) & 39.9 & $36.9^{*}$ \\
\hline Upper secondary (A level+) & 38.1 & 37.6 \\
\hline \multicolumn{3}{|l|}{ Mother's SEG (\%) } \\
\hline I and II & 29.1 & 30.0 \\
\hline III & 45.4 & $40.7^{*}$ \\
\hline IV and V & 8.7 & 9.6 \\
\hline Teenage mothers (\%) & 7.4 & $8.7^{*}$ \\
\hline Mother employed at 33 months (\%) & 52.2 & $49.9^{*}$ \\
\hline \multicolumn{3}{|l|}{ Marital status at 47 months $(\%)$} \\
\hline Never married & 9.7 & 10.7 \\
\hline Married once & 74.9 & $71.5^{*}$ \\
\hline Separated/divorced) & 15.4 & $17.6^{*}$ \\
\hline Mother is vegetarian at birth (\%) & 5.4 & 5.3 \\
\hline \multicolumn{3}{|l|}{ Family variables } \\
\hline \multicolumn{3}{|l|}{ Income at 33 months (\%) } \\
\hline$<\mathrm{f} 200$ & 22.0 & $23.9^{*}$ \\
\hline$£ 200-£ 400$ & 50.2 & $44.9^{*}$ \\
\hline$>£ 400$ & 19.3 & $21.7^{*}$ \\
\hline$\%$ owning home & 83.0 & $78.4^{*}$ \\
\hline \multicolumn{3}{|l|}{ Parenting variables } \\
\hline Mother's teaching practices score at 18 months (mean, range) & $8.0,0-10$ & $8.0,0-10$ \\
\hline Mother's interest in child, score at 18 months (mean, range) & $32.3,11-36$ & $32.2,9-36$ \\
\hline Mother's parenting score at 6 months (mean, range) & $10.5,0-12$ & $10.4,0-12$ \\
\hline Mother's parenting score at 18 months (mean, range) & $40.7,13-51$ & $40.7,6-51$ \\
\hline \multicolumn{3}{|l|}{ Breastfeeding (\%) } \\
\hline Never & 22.7 & $24.7^{*}$ \\
\hline Up to 6 months & 45.6 & 44.9 \\
\hline Over 6 months & 31.8 & 30.3 \\
\hline HOME score (mean, range) & $8,0-12$ & $8,0-12$ \\
\hline Child watches children's programmes $18-42$ months (\%) & 72.7 & $59.5^{*}$ \\
\hline
\end{tabular}

\footnotetext{
Asterisk indicates statistical significance difference in means at $1 \%$ level.

Sample sizes depend on missing information from individual variables. Sample size for available sample fluctuates between 5301 for mothers' employment and 5741 for gender. Sample size for whole ALSPAC cohort fluctuates between 8515 for mother's employment and 12234 for gender and ethnicity.

ALSPAC, Avon Longitudinal Study of Parents and Children; SEG, socioeconomic group.
}

the impact of dietary patterns at ages 3, 4 and 7 on KS1 and KS2 results, controlling for all confounding variables. The final two models estimated the impact of dietary patterns on KS1 controlling for entry assessments, and on KS2 controlling for KS1 attainment, both including all confounding variables. Models 1 and 2 estimate the impact of dietary patterns on the level of attainment, whereas the final model estimates this impact on the change in attainment.

Finally, we investigated the differences in KS2 attainment between children who ate packed lunches and those who ate school meals, controlling for KS1 test scores, food intake prior to school entry (age 3) and other relevant socioeconomic and demographic factors. In this estimation, we focused on the importance of the estimated parameter of packed lunches relative to school meals.

\section{RESULTS}

\section{Data analyses}

Table 2 shows descriptive statistics for the main variables used in the analysis according to whether children were in the top or the bottom 20th percentiles of KS2 results. Children with the highest KS2 scores also had higher average KS1 scores and entry assessment results. Higher "junk" dietary pattern scores at 3, 4 and 7 years were associated with lower average KS2 results. In contrast, a positive association was shown for the "healthconscious" dietary pattern and KS2 results. The "traditional" dietary pattern was not associated with KS2 results. Finally, there was a negative association between eating school meals and attainment whereby a lower proportion of high attaining children eat school meals. The opposite association was shown for packed lunches. 
Table 2 Descriptive statistics for prior attainment and diet data by Key Stage 2 results

\begin{tabular}{|c|c|c|c|c|c|c|}
\hline \multirow[b]{2}{*}{ Variable } & \multicolumn{2}{|c|}{ KS2: lowest $\mathbf{2 0} \%$} & \multicolumn{2}{|c|}{ KS2: middle $\mathbf{6 0} \%$} & \multicolumn{2}{|c|}{ KS2: top $20 \%$} \\
\hline & Mean & SD & Mean & SD & Mean & SD \\
\hline Key Stage $2^{*}$ (KS2) & -1.47 & 0.62 & 0.12 & 0.44 & 1.12 & 0.20 \\
\hline Key Stage $1^{*}(\mathrm{KS} 1)$ & -1.03 & 0.73 & 0.05 & 0.77 & 0.88 & 0.52 \\
\hline Entry Assessments & -0.69 & 0.78 & 0.05 & 0.78 & 0.60 & 0.78 \\
\hline Junk food at 3 years & 0.35 & 1.02 & -0.03 & 0.93 & -0.35 & 0.82 \\
\hline "Health-conscious" at 3 years & -0.26 & 0.83 & -0.08 & 0.96 & 0.13 & 1.03 \\
\hline "Traditional" at 3 years & 0.01 & 0.95 & 0.02 & 1.02 & -0.01 & 0.98 \\
\hline "Junk food" at 4 years & 0.19 & 1.06 & 0.03 & 0.96 & -0.16 & 0.88 \\
\hline "Health-conscious" at 4 years & -0.29 & 0.85 & -0.08 & 0.95 & 0.18 & 1.01 \\
\hline “Traditional” at 4 years & -0.03 & 1.01 & 0.00 & 0.99 & -0.02 & 0.93 \\
\hline "Junk" food at 7 years & 0.24 & 1.06 & 0.06 & 0.96 & -0.15 & 0.88 \\
\hline "Health-conscious" at 7 years & -0.22 & 0.93 & -0.07 & 0.97 & 0.12 & 0.99 \\
\hline \multirow[t]{2}{*}{ "Traditional" at 7 years } & -0.02 & 1.08 & 0.03 & 1.00 & -0.04 & 0.91 \\
\hline & \multicolumn{2}{|c|}{ Proportion } & \multicolumn{2}{|l|}{ Proportion } & \multicolumn{2}{|c|}{ Proportion } \\
\hline School meals (\%) & \multicolumn{2}{|c|}{22.0} & \multicolumn{2}{|l|}{17.6} & \multicolumn{2}{|c|}{16.5} \\
\hline Packed lunches (\%) & \multicolumn{2}{|l|}{39.1} & \multicolumn{2}{|l|}{41.3} & \multicolumn{2}{|l|}{43.0} \\
\hline Observations & \multicolumn{2}{|l|}{1149} & \multicolumn{2}{|l|}{3444} & \multicolumn{2}{|l|}{1148} \\
\hline
\end{tabular}

*National tests, Key Stage 1 taken at ages 6-7 and Key Stage 2 at ages 10-11.

\section{Dietary patterns at different ages in childhood and school attainment}

Figure 1 shows the results from a regression analysis of dietary patterns at different ages on three measures of school attainment, controlling for confounding factors. The main result is that the "junk food" dietary pattern was more strongly associated with school attainment at age 3 than at later ages. Increased "junk food" scores were negatively associated with attainment even after adjusting for all confounding variables. Moreover, although the impact of other dietary patterns on attainment fluctuated around zero (once the age 3 measure was included), the impact of "junk food" score at 3 was always negative and of substantive magnitude.

\section{Change in attainment conditional on previous attainment}

We modelled change in attainment from entry assessments to KS1 and from KS1 to KS2. Increasing "junk food" score at 38 months was negatively associated with an increase in school attainment for both time periods. Moreover, the measures of early (pre-school) dietary patterns were more predictive of school success than later measures of diet (table 3).

Second, the estimated coefficient of the "junk food" dietary pattern at age 3 on KS2 attainment was smaller than that on KS1 attainment, after controlling for prior attainment. One standard deviation increase in the score of "junk food" dietary component at 38 months was associated with a decrease of $0.027(2.7 \%$ of a standard deviation) in the KS2 and of 0.065 $(6.5 \%)$ in the KS1 score. Further, one standard deviation increase in the score of the "health-conscious" dietary component at 38 months was associated with an increase of 3.9 per cent of a standard deviation in the KS2, larger than that on KS1, and no association in the KS1 score. However, when compared with the impact of prior attainment on current attainment, which fluctuates between 53 per cent and 69 per cent of standard deviation, these are relatively small changes (table 3 ).

In subgroup analysis, we found a negative socioeconomic gradient for the relationship between "junk food" dietary pattern and school attainment, but only between those in the highest SEG and the rest of the population. The estimated effect for the highest socioeconomic group was the lowest (-0.021); the effect for the middle socioeconomic group was -0.046 and finally the effect for the lowest socioeconomic group was
-0.043 . However, we found no evidence that SEG moderated the relationship between dietary patterns and attainment.

\section{School meals or packed lunches and KS2 results}

We found no difference in the average increase of KS2 scores between children who ate packed lunches 5 days a week and children who ate school meals 5 days a week or children who ate school meals 5 days a week and children who had some combination of packed lunches and school meals during the school week (table 4). This result was robust to the inclusion of prior attainment and consumption of "junk food" at age 3, differentiating for a free school meal indicator (column 1) and to the inclusion of other confounding variables (column 2).

\section{DISCUSSION}

For the children in this sample, an increased score on the "junk food" pattern at age 3 was associated with lower results in KS2 tests. An opposite association was found for the "healthconscious" dietary pattern score and school attainment. Further, when confounding factors were taken into account, the impact of increased pre-school "junk food" dietary pattern remained a risk factor for poor school attainment. This result is consistent with other findings suggesting that nutritional deficiencies prior to school entry have the potential to negatively impact upon cognitive outcomes in school-aged children. ${ }^{19}$ Though contested, intake of foods high in sugar may also be associated with behavioural problems, such as hyperactivity, that can interfere with attention in the classroom and thus attainment, another potential explanation for these findings. ${ }^{8} 20$

Although there was a negative association between early "junk food" consumption and later attainment scores, the estimated effect was small, suggesting that nutrition may have a diminishing role in attainment as children grow older, when the effect is more likely to be mediated by prior attainment. This may indicate a developmental period or stage where children are more susceptible to the long-term cognitive impact of poor nutrition. There is potential for a stronger effect as this sample is slightly biased towards more educated, middle class, and health-conscious mothers, though there was no evidence that socioeconomic status of the family mediated this relationship. 

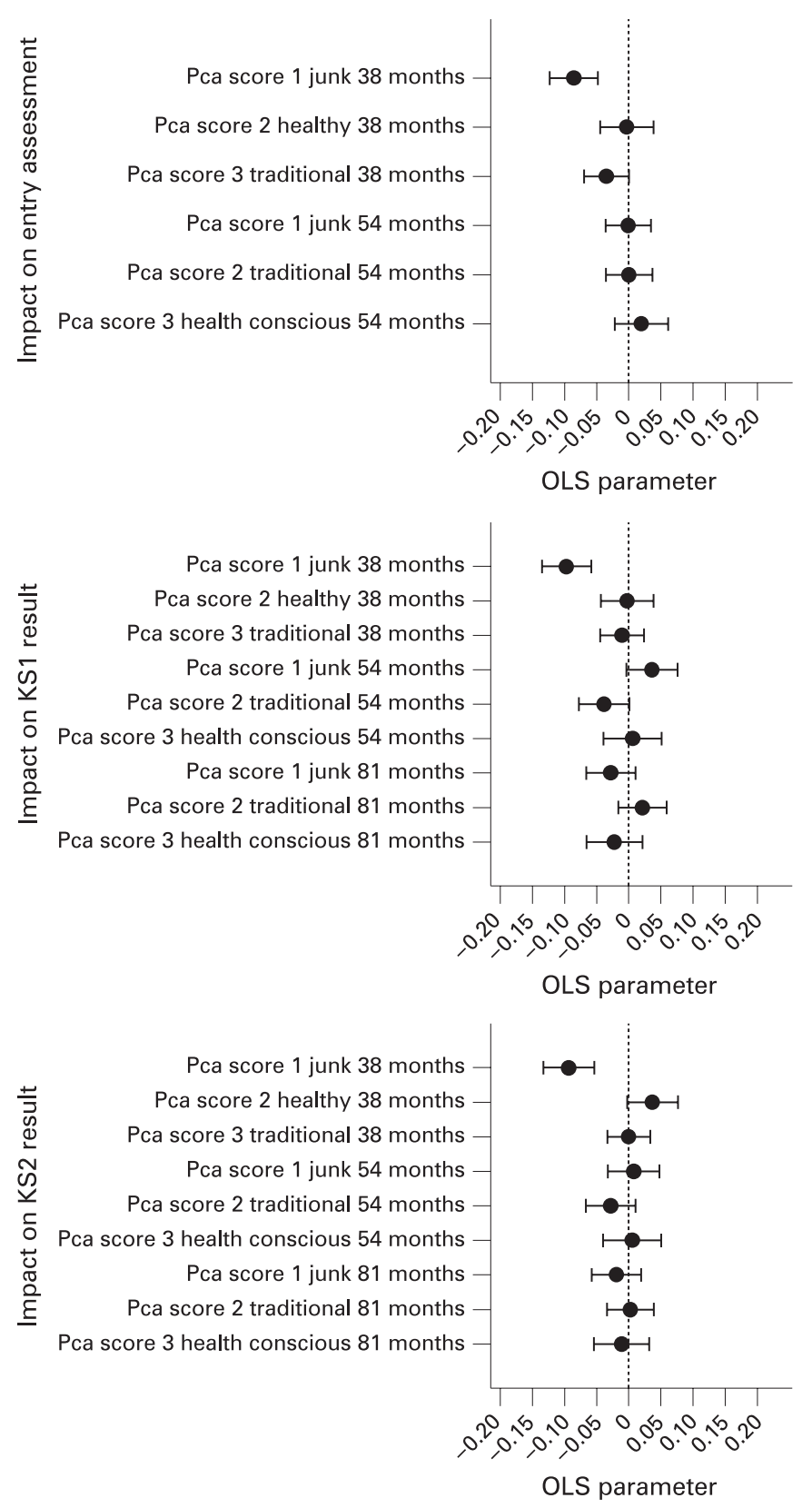

Figure 1 Parameter estimates of dietary patterns on different measurements of attainment. OLS, ordinary least squares; Pca, principal components analysis.

There was no relationship between school meals or packed lunch consumption and later attainment once the "junk food" dietary pattern prior to school entry and other confounding factors were introduced in the analysis. This suggests that although the emphasis on school meals is valuable and important, it must be part of a wider concern with nutrition more generally, in homes, in packed lunches and in school meals.

Full data were available on only 41 per cent of the original cohort and there were fewer ethnic minorities and disadvantaged families in this group than in the original cohort. Therefore, it was important to take account of these variables in the statistical models used. With a longitudinal research design, it is possible to account for some of the confounding bias in the relationship between dietary patterns and school attainment. For instance, mothers' health beliefs, educational
Table 3 Ordinary least squares (OLS) regression of increase in attainment and dietary patterns at 3,4 and 7 years

\begin{tabular}{|c|c|c|c|c|}
\hline \multirow[b]{2}{*}{ Variable } & \multicolumn{2}{|l|}{ KS2† } & \multicolumn{2}{|l|}{ KS1† } \\
\hline & Coefficient & SE & Coefficient & SE \\
\hline $\begin{array}{l}\text { Prior attainment } \\
\text { scores }\end{array}$ & 0.687 & $(0.013)^{* *}$ & 0.533 & $(0.016)^{* *}$ \\
\hline $\begin{array}{l}\text { "Junk food" at } 3 \\
\text { years }\end{array}$ & -0.027 & $(0.014)^{*}$ & -0.065 & $(0.019)^{* *}$ \\
\hline $\begin{array}{l}\text { "Health-conscious" } \\
\text { at } 3 \text { years }\end{array}$ & 0.039 & $(0.015)^{* *}$ & -0.002 & $(0.020)$ \\
\hline $\begin{array}{l}\text { "Traditional" at } 3 \\
\text { years }\end{array}$ & 0.007 & $(0.012)$ & 0.004 & $(0.017)$ \\
\hline $\begin{array}{l}\text { "Junk food" at } 4 \\
\text { years }\end{array}$ & -0.017 & $(0.014)$ & 0.036 & $(0.020)$ \\
\hline $\begin{array}{l}\text { "Health-conscious" } \\
\text { at } 4 \text { years }\end{array}$ & 0.001 & $(0.017)$ & 0.014 & $(0.023)$ \\
\hline $\begin{array}{l}\text { "Traditional" at } 4 \\
\text { years }\end{array}$ & -0.002 & $(0.014)$ & -0.039 & $(0.019)^{*}$ \\
\hline $\begin{array}{l}\text { "Junk food" at } 7 \\
\text { years }\end{array}$ & 0.000 & $(0.014)$ & -0.005 & $(0.019)$ \\
\hline $\begin{array}{l}\text { "Health-conscious" } \\
\text { at } 7 \text { years }\end{array}$ & 0.004 & $(0.015)$ & -0.022 & $(0.022)$ \\
\hline $\begin{array}{l}\text { “Traditional" at } 7 \\
\text { years }\end{array}$ & -0.012 & $(0.013)$ & 0.018 & $(0.018)$ \\
\hline $\begin{array}{l}\text { Child variables } \\
\text { included }\end{array}$ & Yes & & Yes & \\
\hline $\begin{array}{l}\text { Mother variables } \\
\text { included }\end{array}$ & Yes & & Yes & \\
\hline $\begin{array}{l}\text { Child-mother } \\
\text { processes included }\end{array}$ & Yes & & Yes & \\
\hline Observations & 4244 & & & 4098 \\
\hline
\end{tabular}

Robust and cluster $t$ statistics in parentheses.

${ }^{*}$ Significant at $5 \%$; ** significant at $1 \%$.

† National tests, Key Stage 1 (KS1) taken at ages 6-7 and Key Stage 2 (KS2) at ages $10-11$.

attitudes and parenting behaviours may impact upon the provision of healthy food at home and provision of an educational environment, thus confounding the relationship. ${ }^{21}$ In as much as we have information about the mother, via the HOME score and other measures, we can condition out some of the confounding bias. Still, results from this paper do not prove causality.

We used FA to reduce $\mathrm{KS}$ results on maths, science and English into a single variable related to school attainment. We also relied on the dietary patterns identified using FA. ${ }^{17} 18$ This method for obtaining dietary patterns has been criticised for its subjectivity in identifying the underlying patterns. ${ }^{22}$ It has also

Table 4 Ordinary least squares (OLS) regression of KS2 attainment: packed lunch versus adjusted for free school meals, conditioning on free school meals (1) and child and mother characteristics (2)

\begin{tabular}{lcc}
\hline Variables & $\mathbf{1}$ & $\mathbf{2}$ \\
\hline Key Stage 1 (KS1) scores $\dagger$ & $0.706(73.34)^{* *}$ & $0.686(51.58)^{* *}$ \\
Mixed consumption of school meals and & $-0.019(0.73)$ & $0.009(0.29)$ \\
lunches & $0.012(0.51)$ & $0.039(1.33)$ \\
Packed lunches only & $-0.089(9.40)^{* *}$ & $-0.032(2.52)^{*}$ \\
"Junk food" score at 38 months (low to & $-0.147(3.73)^{* *}$ & $-0.061(1.00)$ \\
high) & No & Yes \\
FSM indicator for children & No & Yes \\
Child variables included & No & Yes \\
Mother variables included & &
\end{tabular}

Robust and cluster $t$ statistics in parentheses.

${ }^{*}$ Significant at $5 \%{ }^{* *}$ significant at $\%$. Categories for comparison: for mixed consumption of school meals and lunches and packed lunches: (school meals). †National tests: Key Stage 1 taken at ages 6-7. 


\section{What this study adds}

- Previous research has shown that nutrition is related to the cognitive ability of children in the short and long term.

- This paper is the first to link nutrition in early childhood with specific educational attainment outcomes in a dataset as rich as the Avon Longitudinal Study of Parents and Children (ALSPAC).

- After controlling for a number of socioeconomic, demographic and lifestyle factors, we found a negative relationship between nutrition at age 3 and later scores on standardised tests.

\section{Policy implications}

This research highlights the importance of diet before entry into formal education for later school attainment and calls for a concerted effort between schools, families, government departments and other agencies to improve the nutritional intake of children.

been argued that FA is population specific, and, as such, the results reported here may not be replicated in other studies. Despite this, previous research with different populations has linked diet and aspects of school performance. ${ }^{11}$

This study has extended this area of research by linking children's diet before entry into formal education with outcomes for later school attainment. This highlights a challenge for policy-makers in establishing the location of responsibility for school outcomes related to aspects of health. The recent debate in the UK on school dinners has placed the onus on government agencies responsible for education to respond to the health needs of children to improve their educational outcomes. But if educational outcomes in part depend on nutritional intake before the start of school, with whom does responsibility lie? At what stage are interventions most effective? Is money best spent on school dinners or on the provision of health information to new mothers? This further supports movements towards collaborative efforts between agencies, but highlights the challenge of designing policy when the outcomes of one agency rely upon the inputs of another. ${ }^{23}$ Improving the nutritional intake of children in the UK calls for a concerted effort between schools, families, government departments and other agencies to improve diets inside and out of school.

Acknowledgements: We are extremely grateful to all the families who took part in this study, the midwives for their help in recruiting them, and the whole ALSPAC team, which includes interviewers, computer and laboratory technicians, clerical workers, research scientists, volunteers, managers, receptionists and nurses. The UK Medical Research Council, the Wellcome Trust and the University of Bristol provide core support for the Avon Longitudinal Study of Parents and Children and the Smith Institute for funding the research project.
Author contributions: Leon Feinstein, Ricardo Sabates and Annik Sorhaindo carried out the analysis of the data and wrote the first draft of the paper. David Herrick compiled the school assessment data, Pauline Emmett and Imogen Rogers designed and led the dietary data collection within ALSPAC, Kate Northstone produced the dietary patterns scores from the original ALSPAC questionnaires. All authors were responsible for critical revisions and final approval of the manuscript.

Competing interests: All authors declare that they had no financial or personal interest with the funding agency or any other agency related to the topic of this article.

\section{REFERENCES}

1. World Health Organization. Nutrition for health and development. Geneva: World Health Organization, 2000.

2. Darnton-Hill I, Nishida C, James WPT. A life course approach to diet, nutrition and the prevention of chronic diseases. Public Health Nutr 2004;7:101-21.

3. Nishida C, Uauy R, Kumanyika S, et al. The joint WHO/FAO expert consultation on diet, nutrition and the prevention of chronic diseases: process, product and policy implications. Public Health Nutr 2004; 7:245-50.

4. Taras H. Nutrition and student performance at school. J Sch Health 2005;75:199-213.

5. Channel 4. Jamie's school dinners. Available online at: http://www.channel4.com/ life/microsites/J/jamies school dinners/ (accessed September 2005).

6. Lancet. Jamie Oliver for chief medical officer. Lancet 2005;365:1282

7. BBC News. Food for thought. 18 March 2005. http://news.bbc.co.uk/go/pr/fr/-/hi/ magazine/4358415.stm. (accessed Mar 2005).

8. Bellisle F. Effects of diet on behaviour and cognition in children. Br J Nutr 2004; (suppl. 2):S227-32.

9. Pollitt $\mathbf{E}$, Cueto $\mathrm{S}$, Jacoby ER. Fasting and cognition in well- and undernouished schoolchildren: a review of three experimental studies. Am J Clin Nutr 1998;67(suppl):779S-84S

10. Pollitt E, Gorman KS. Nutritional deficiencies as developmental risk factors. In Nelson CA, ed., Threats to optimal development: integrating biological, psychological and social risk factors. New Jersey: Lawrence Erlbaum Associates, 2004.

11. Arija V, Esparo G, Fernandez-Ballart J, et al. Nutritional status and performance in test of verbal and non-verbal intelligence in 6 year old children. Intelligence 2006;34:141-9.

12. Sandstead HH. Causes of iron and zinc deficiencies and their effects on the brain J Nutr 2000;130:347S-349S

13. Bryan J, Osendarp S, Hughes D, et al. Nutrients for cognitive development in schoolaged children. Nutr Rev 2004;62:295-306.

14. Rogers IS, Ness AR, Hebditch $\mathrm{K}$, et al. The quality of food eaten in English primary schools: school dinners versus packed lunches. Eur J Clin Nutr 2007;61:856-64.

15. Golding J, Pembrey M, Jones R, et al. ALSPAC-The Avon Longitudinal Study of Parents and Children. I. Study methodology. Paediatric Perinatal Epidemiol 2001;15:74-87.

16. Caldwell BM, Bradley RH. Home observation for measurement of the environment Little Rock: University of Arkansas at Little Rock, 1984.

17. North K, Emmett P, and the Avon Longitudinal Study of Pregnancy and Childhood (ALSPAC) Study Team. Multivariate analysis of diet among three-year-old children and associations with socio-demographic characteristics. Eur J Clin Nutr 2000;54:73-80.

18. Northstone K, Emmett P, and the ALSPAC Study Team. Multivariate analysis of diet in children at four and seven years of age and associations with socio-demographic characteristics. Eur J Clin Nutr 2005:59:751-760.

19. Wiles N, Northstone K, Emmett P, et al. "Junk" food diet and childhood behavioura problems. Results from the ALSPAC cohort. Eur J Clin Nutr 2007. Published Online First. DOI: 10.1038/sj.ejcn.1602967

20. Wolraich ML, Lindgren SD, Stumbo PJ, et al. Effects of diets with high sucrose or aspartame on the behaviour and cognitive performance of children. N Engl J Med 1994;330:303-7.

21. Rogers I, Emmett PM, ALSPAC Study Team. The effect of maternal smoking status, educational level and age on food and nutrient intakes in preschool children: results from the Avon Longitudinal Study of Parents and Children. Eur J Clin Nutr 2003:57:854-64.

22. Martinez ME, Marshall JR, Sechrest L. Invited commentary: Factor analysis and the search for objectivity. Am J Epidemiol 1998;148:17-19.

23. Feinstein L, Sabates R, Anderson TM, et al. The effects of education on health: Concepts, evidence and policy implications. A review for the OECD Centre for Educational Research and Innovation (CERI). Paris: CERI 2006. 


\section{APPENDIX}

Table A1. Comparison of dietary intake amongst children with diets high or low in "junk food" based on dietary intake at age $41 / 2$ years

\begin{tabular}{|c|c|c|c|c|c|}
\hline \multirow[b]{2}{*}{$\begin{array}{l}\text { Frequency of consumption of food } \\
\text { item at least } 4 \text { times per week }\end{array}$} & \multicolumn{2}{|c|}{ Percentage of children in } & \multirow[b]{2}{*}{$\begin{array}{l}\text { Frequency of consumption of food } \\
\text { item at least } 4 \text { times per week }\end{array}$} & \multicolumn{2}{|c|}{ Percentage of children in } \\
\hline & $\begin{array}{l}\text { Lowest quintile of } \\
\text { "junk food" (\%) }\end{array}$ & $\begin{array}{l}\text { Highest quintile of } \\
\text { "junk food" (\%) }\end{array}$ & & $\begin{array}{l}\text { Lowest quintile of } \\
\text { "junk food" (\%) }\end{array}$ & $\begin{array}{l}\text { Highest quintile o } \\
\text { "junk food" (\%) }\end{array}$ \\
\hline Crispy coated chicken/turkey & 1.2 & 16.7 & Sausages/burgers & 0.2 & 3.7 \\
\hline Crisps & 12.8 & 71.0 & Baked beans & 2.1 & 13.0 \\
\hline Ice cream & 0.7 & 29.9 & Tinned pasta & 1.2 & 14.6 \\
\hline Cake & 4.8 & 29.5 & Pasta & 9.7 & 7.2 \\
\hline Chocolate bars & 3.6 & 46.2 & Other fresh fruit & 20.7 & 19.3 \\
\hline Sweets & 1.3 & 34.5 & Green leafy vegetables* & 0.2 & 0.3 \\
\hline Cola/Other fizzy drinks & 3.0 & 33.6 & Other green vegetables $\dagger$ & 0.3 & 0.3 \\
\hline Ice lollies & 0.2 & 22.9 & Carrots & 0.5 & 0.5 \\
\hline Milk-based puddings & 2.0 & 15.6 & Other root vegetables: & 0.1 & 0.2 \\
\hline
\end{tabular}

${ }^{*}$ Cabbage, brussel sprouts, spinach, broccoli and other dark green leafy vegetables

†Other green vegetables (cauliflower, runner beans, leeks, okra, courgettes, etc.)

\$0ther root vegetables (turnip, swede, parsnip, etc.) 